\title{
Enhanced Diversity at Network Nodes: River Confluences Increase Vegetation-Patch Diversity
}

\author{
Takeshi Osawa $^{*}, 1,4$, Hiromune Mitsuhashi ${ }^{2}$, Hideyuki Niwa ${ }^{3}$ and Atushi Ushimaru ${ }^{1}$ \\ ${ }^{1}$ Graduate School of Human Development and Environment, Kobe University, 3-11, Tsurukabuto, Nada-ku, Kobe city, \\ Hyogo pref, 657-8501, Japan \\ ${ }^{2}$ The Museum of Nature and Human Activities Hyogo, 6 Yayoigaoka, Sanda Hyogo pref 669-1546, Japan \\ ${ }^{3}$ The Graduate School of Global Environmental Studies, Kyoto University, Yoshida-Honmachi, Sakyo-ku, Kyoto pref \\ 606-8501, Japan \\ ${ }^{4}$ National Institute for Agro-Environmental Science, 3-1-3 Kannondai, Tsukuba, Ibaraki pref 305-8604, Japan
}

\begin{abstract}
Although dendritic networks within ecosystems have typically been considered a special case of network topology, they have attracted a great deal of attention in recent years. These systems exhibit unique features in that both the nodes and branches provide distinct habitats. Within a river discontinuum context, river confluences, which are nodes of dendritic river networks, are hypothesised to have particular hydrodynamic traits that create heterogeneous habitats through a unique disturbance regime, although this hypothesis has not yet been tested. We tested this hypothesis using a vegetation data set collected from 14 river basin systems in Hyogo Prefecture, Japan. We compared vegetation-patch diversity between confluence and single-flow areas using hierarchical Bayesian models. Our results demonstrated greater vegetation-patch diversity in confluence areas compared to single-flow areas. Our findings support the hypothesis that confluences result in highly heterogeneous habitats. To the best of our knowledge, this is the first empirical report to demonstrate that river confluences have high vegetation-patch diversity. We conclude that network nodes play an important role in maintaining the biodiversity of river networks.
\end{abstract}

Keywords: Disturbance, geography, habitat heterogeneity, hierarchical Bayesian model, river channel network.

\section{INTRODUCTION}

Recent syntheses have used network theoretical analysis to understand the functioning of diverse sets of complex ecological systems (May 2006; Montoya et al. 2006). These analyses have suggested that emergent characteristics such as system-level responses to disturbance can be predicted from the structure of a network and the strength of interactions among network elements (Grant et al. 2007). Although dendritic networks within ecosystems are usually considered a special case of network topology (Grant et al. 2007), they have attracted a great deal of attention in recent years. Such systems exhibit the distinctive feature that both the nodes and branches provide unique habitats (Benda et al. 2004a; Benda et al. 2004b; Grant et al. 2007).

In dendritic networks, nodes provide high-quality habitats (Grant et al. 2007). River confluences, which correspond to the nodes of dendritic river networks, are known to exhibit particular hydrodynamic traits (Rhoads \& Kenworthy 1995; De Serres et al. 1999; Benda et al. 2004a; Benda et al. 2004b; Rice et al. 2008) that result in many geomorphically diverse habitats (Benda et al. 2004b; Rice et al. 2008). In river ecosystems, flooding-induced disturbances, which pro-

*Address correspondence to this author at the Graduate School of Human Development and Environment, Kobe University, 3-11, Tsurukabuto, Nada$\mathrm{ku}$, Kobe city, Hyogo pref, 657-8501, Japan; Tel: +81.78.803.7882; Fax:+81.78.803.7820; E-mail: arosawa@gmail.com

Handling Editor: Philip H. Crowley vide the most dynamic and complex biophysical habitats (Naiman et al. 1993; Burkart 2001), occur more frequently at confluences (Benda et al. 2004b). Thus, confluences are considered to increase spatial and temporal habitat heterogeneity (Benda et al. 2004a; Benda et al. 2004b; Rice et al. 2008). Benda et al. (2004a, b) reviewed several cases of habitat creation by confluences, e.g., the formation of fans and erosion-resistant deposits, which may influence biodiversity (Benda et al. 2004a; Benda et al. 2004b). However, the roles of confluences in creating habitat heterogeneity (confluence effects) within river ecosystems have rarely been examined, but they should be investigated within a context of maintaining biodiversity in river ecosystems.

Habitats in river systems are characterised by differences in river streams and reaches, which join together to form larger networks (Lowe et al. 2006). Therefore, an effective analysis of the ecological importance of a river confluence as a component of the river channel network must incorporate the entire river channel network. Ideally, this kind of analysis applies data collected from many rivers that constitute various river channel networks (Benda et al. 2004b). This type of approach helps to minimise individual river systemspecific "noise" when analysing confluence effects (Knick et al. 2008). However, few wide-area biodiversity data sets from many river systems are available, because data collection is often expensive and time-consuming (e.g., Svensson et al. 2007; Haddad et al. 2008). From 2002 to 2006, the Hyogo Prefecture government in Japan conducted the Research about the Natural Environment of Rivers (RNER) 
program for all rivers within the prefecture. This program involved investigating riparian vegetation for 195 individual rivers in 14 river basin systems, over an area of 5105 ha. All data were digitised and then incorporated into a geographic information system (GIS) (Hyogo Prefecture 2007). We used the RNER riparian vegetation data to determine whether diversity in vegetation patches, which serve as potential habitat, increases around confluences of Hyogo Prefecture rivers. High physical heterogeneity may augment biological diversity via the well-established principle that biological diversity tends to increase with habitat variability (Benda et al. 2004b; Rice et al. 2008).

We analysed the RNER data set to determine how river confluences affect habitat heterogeneity using a hierarchical Bayesian model that included three hierarchical random effects (see "METHODS" section). In the RNER vegetation data set, different vegetation types were illustrated as patches on a vegetation map. The 17 vegetation types correspond to different habitat types in the RNER (Hyogo Prefecture
2009). We used Shannon and Simpson diversity indices of vegetation patches as indices of habitat diversity and compared these between confluence sites and non-confluence sites. The following sections present our findings and discuss the significance of river confluences in riparian ecosystems.

\section{METHODS}

\section{Research About the Natural Environment of Rivers (RNER) Data Set}

We used the RNER vegetation data set from surveys conducted between 2002 and 2006 (Fig. 1) to investigate riparian vegetation in alluvial river sections (total length, 680 $\mathrm{km}$ ). The RNER vegetation data set was created using two steps. The first step involved identification of the edges of vegetation patches from aerial photographs and digitalisation of vegetation patches on a 1/2500 contour map. Color photographs (scale: 1/10,000) taken by the Hyogo Prefecture



Fig. (1). Watersheds and main streams of analyzed river basin systems in Hyogo Prefecture. 
Table 1. Vegetation types in the RNER Data Set and Explanation of Indication Habitats. Definitions are Detailed in Hyogo Prefecture (2009)

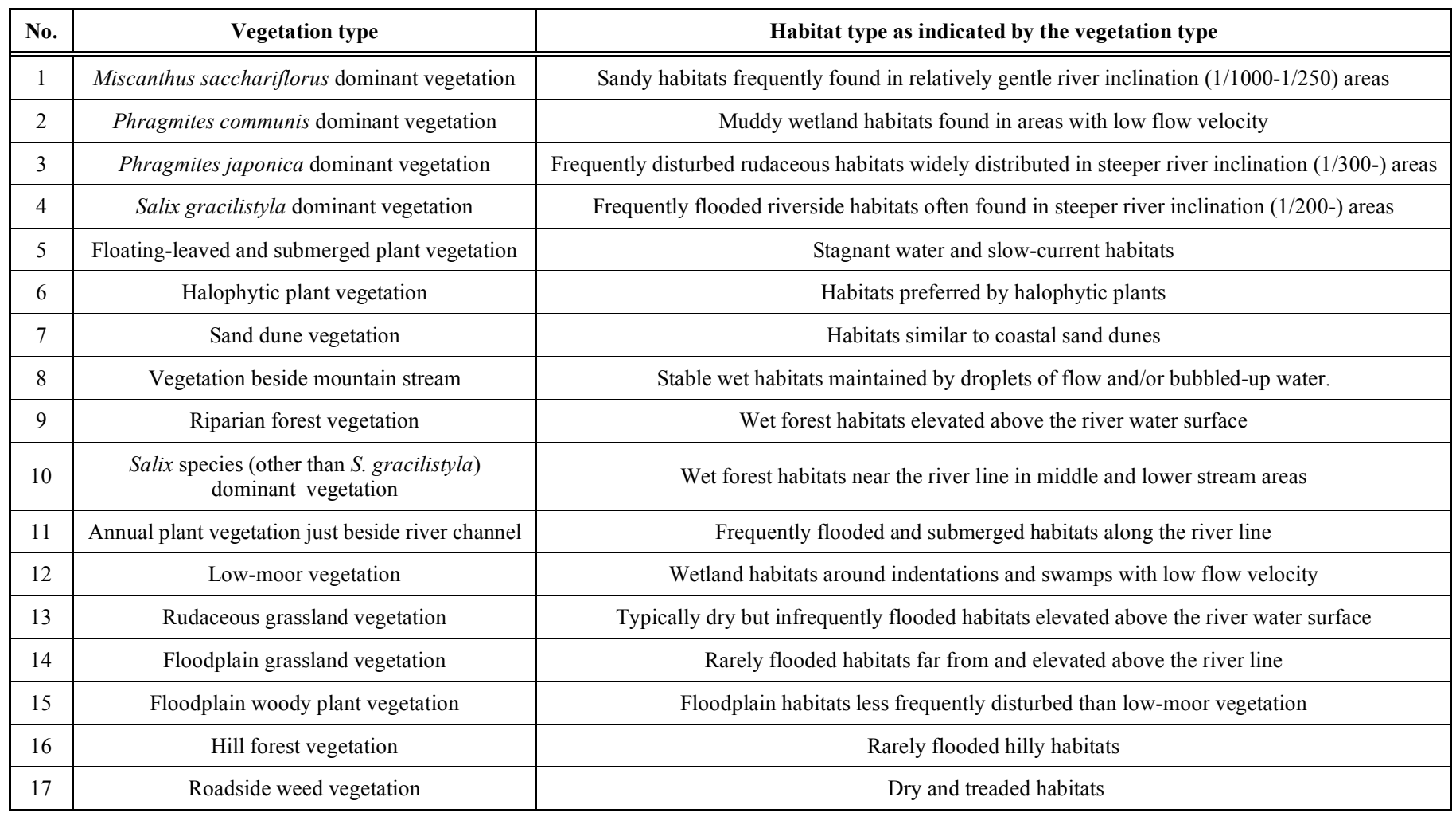

government were used for patch identification. After the creation of the vegetation patch map, extensive field surveys using the Braun-Blanquet approach (i.e., phytosociological surveys) were conducted to classify the types of vegetation within the patches (Hyogo Prefecture 2002, 2007). Because surveying all vegetation patches would be prohibitively time-consuming, the phytosociological surveys were conducted on arbitrarily selected patches for each vegetation type. The data set first classified vegetation patches into 17 types based on habitat types that were estimated from dominant species and their life form (Table 1). In addition, land use and unvegetated areas (e.g., natural bare ground, open water, and artificial areas) were also classified into five types, and the vegetation/land-use types were summarised as patches on a vegetation map (Fig. 2). Vegetation was mainly distributed within $50-\mathrm{m}$ of the river line, and each vegetation patch was entered as digital polygon data into GIS (ArcGIS version 9.1; ESRI Co., Tokyo, Japan).

In this study, we used the 17 vegetation types to evaluate habitat heterogeneity, as this vegetation classification system was intended to categorise habitats for plants along river lines of Hyogo Prefecture (Hyogo Prefecture 2009; Table 1).

\section{Data Preparation}

We used GIS software (ArcGIS) to divide river lines into 500-m units along all rivers of Hyogo Prefecture; each 500$\mathrm{m}$ unit was a 500-m long and approximately 400-m wide polygon (Fig. 2). The first 500-m unit was placed at the mouth of each river, and the other 500-m units were then set automatically along river lines starting from the first unit using GIS. When a single vegetation patch was encompassed by two $500-\mathrm{m}$ units, the patch was divided into two $500-\mathrm{m}$ units. We defined a 500-m unit adjacent to more than three other units and including a river confluence as a "confluence unit", whereas a 500-m unit adjacent to two or fewer other units and not including a river confluence was considered a "single-flow unit" (Fig. 2). A total of 190 units were classified as confluence units, and 1293 units were classified as single-flow units. We also calculated the area of all patches of vegetation within each $500-\mathrm{m}$ unit. We then calculated Shannon $\left(H^{\prime}\right)$ and Simpson $(D)$ diversity indices of vegetation patches for each unit as follows:

$$
\begin{gathered}
H^{\prime}{ }_{x}=-\sum_{i=1}^{N}\left(a_{i} / A_{x}\right) \operatorname{In}\left(a_{i} / A_{x}\right), \\
D_{x}=1-\sum_{i=1}^{N}\left(a_{i} / A_{x}\right)^{2},
\end{gathered}
$$

where $\mathrm{N}$ is the number of vegetation types within the unit $x$, $A_{x}$ is the total vegetation area of the unit, and $a_{i}$ is the area of vegetation $i$. Finally, we calculated the total vegetation area and stream power index (SPI) per unit. SPI is the product of river-bed inclination and basin area and is generally used as an index of the erosive power of flowing water (Wilson \& Gallant 2000). These two factors may affect vegetation diversity in riparian areas; therefore, we incorporated them into the models to control for their effects when determining confluence effects. 


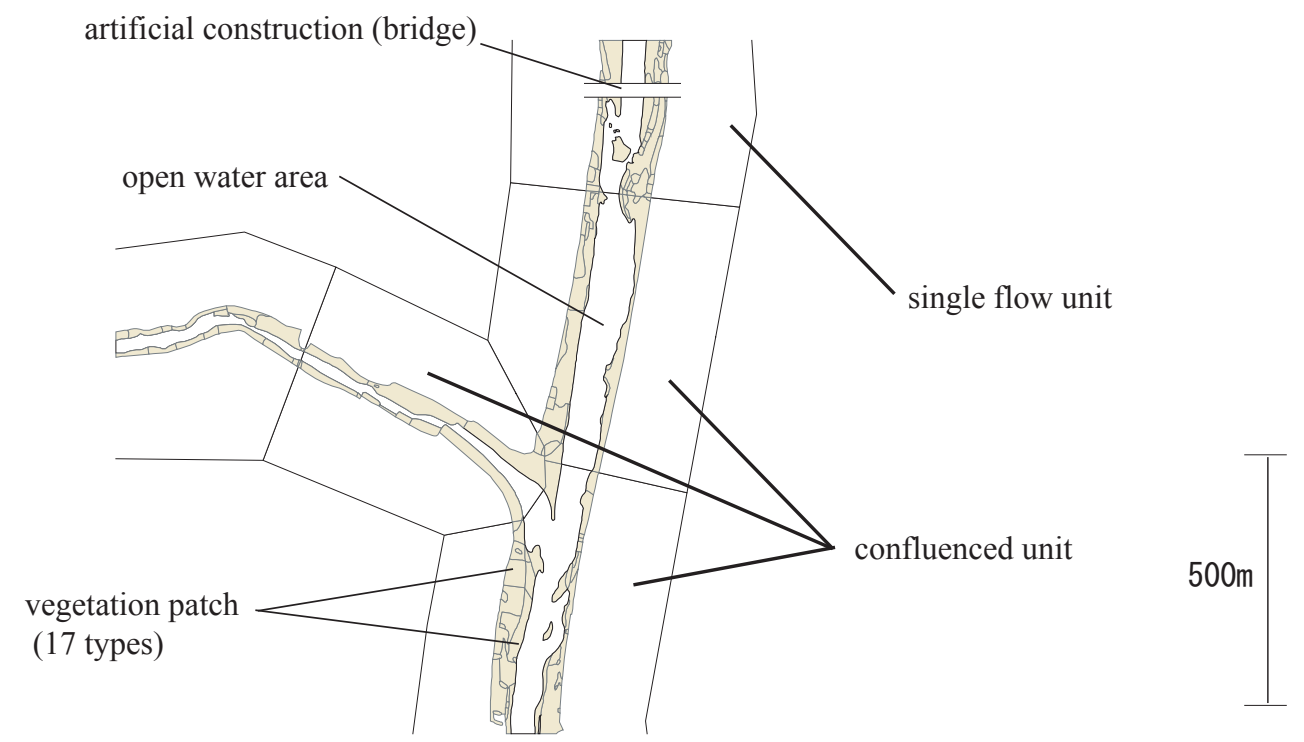

Fig. (2). Example of the Research about the Natural Environment of Rivers (RNER) geographic information system (GIS) data. Square polygons represent individual units. Confluence and single-flow units are defined as units adjacent to more than three other units and two other units, respectively. The central white polygon represents open water, and the other small polygons represent classified vegetation patches.

\section{Pre-Specified Conditions}

Data sets for river channel networks have a hierarchical construction: flows compose reaches, which link together to form larger stream networks (Lowe et al. 2006). Each of these components has unique traits. In addition, when a large-scale data set such as the RNER data set is analysed, the power of statistical analyses is often influenced by variation among data collectors, data sampling dates, and noninvestigated site characteristics (Link 1999; Link \& Sauer 2002; Clark et al. 2003; Thogmartin et al. 2004). Additionally, environmental factors are usually spatially auto-

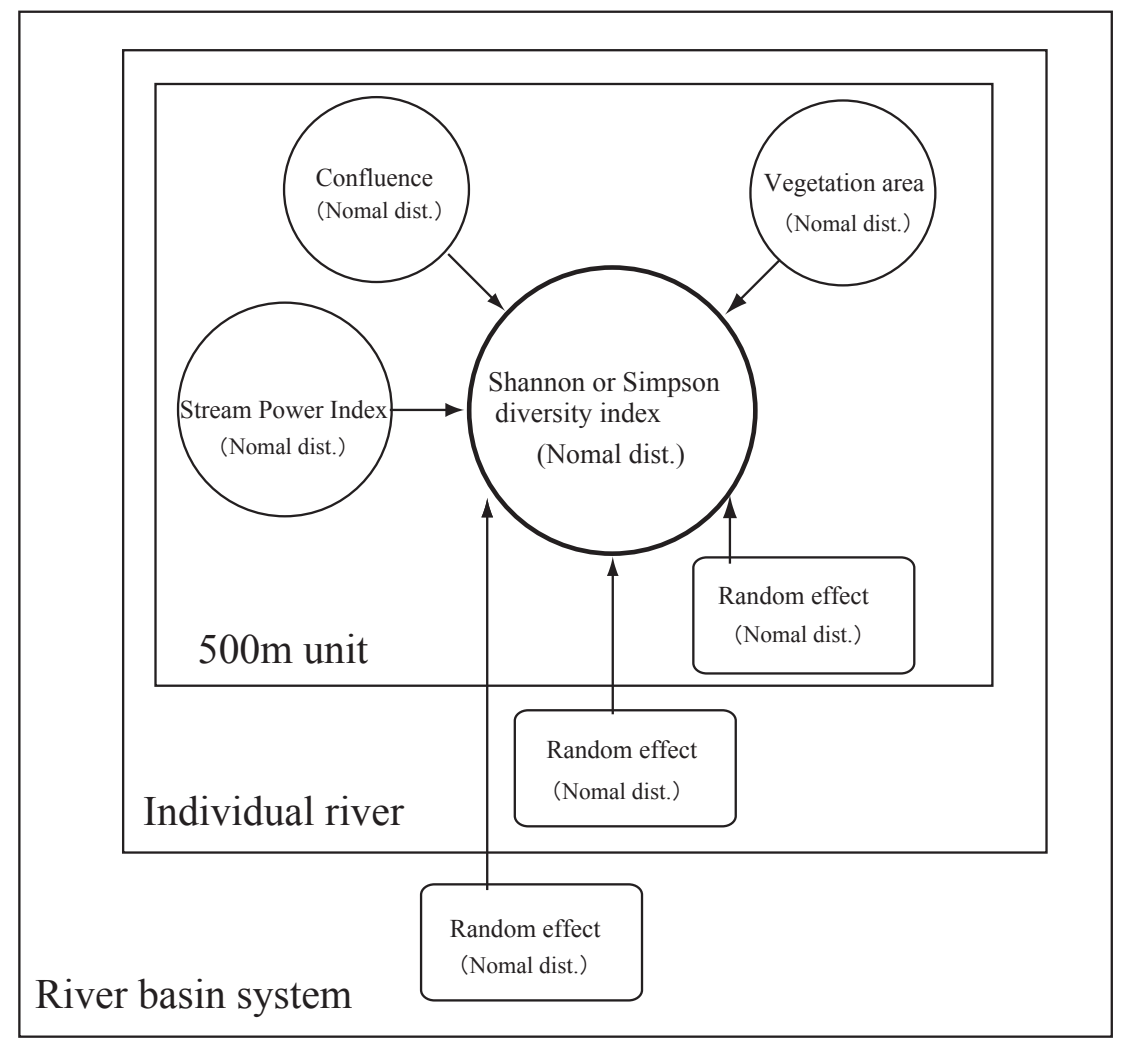

Fig. (3). Conceptual diagram of nested random effect models. The central circle represents the vegetation diversity index (patch number, Shannon $H^{\prime}$, or Simpson $D^{\prime}$ ). The surrounding circle represents fix effects, and the wavy square represents random effects. 
correlated (e.g., Keitt et al. 2002). To minimise these issues, multiple types of random effects should be incorporated into models (Link \& Sauer 2002). The use of random effects is an effective method for data summarisation; i.e., the reduction of many parameters into simple summaries (Link 1999). The top-ranked random effect used in our analysis was river basin systems, which are related to variation in river length, catchment area, landform, and other traits. The secondranked random effect is individual rivers, which are related to the diversity of types and scales of human land use and artificial constructions. The bottom-ranked rank random effect is individual $500-\mathrm{m}$ units, which are related to unobserved micro-environmental factors such as observer error. Our models incorporated a nested structure of these three random effects, which were treated as mean zero normal random variables (Fig. 3).

\section{Model Establishment}

We established hierarchical Bayesian models that included three hierarchical random effects. Shannon $H^{\prime}$ and Simpson $D$ were assumed to have normal distributions. Our models can be expressed as:

$Y_{i j k} \sim \operatorname{Normal}\left(\alpha_{\mathrm{k}}, \mathrm{V}\right)$,

$\alpha_{k}=$ Intercept $+\operatorname{conf}_{k}+S P I_{k}+$ area $_{k}+R_{i}+R_{j}+R_{k}$, and

$V=$ Variance of each diversity index,

where $Y_{i j k}$ is Shannon $H^{\prime}$ or Simpson $D^{\prime}$ in a 500-m unit $k$ on river $j$ of river system $i$. We used the effects of three physical parameters as fixed effects: the presence of a river confluence (conf, 1, or 0); stream power index (SPI); and total vegetation area (area) of a unit. We also incorporated three random effects: river system, individual river, and individual unit ( $R_{i}, R_{j}$, and $R_{k}$, respectively).

A necessary initial consideration in a Bayesian analysis is that prior distributions for each variable are informed (Link \& Sauer 2002; Thogmartin et al. 2004). Because we had little empirical support for one distribution over another, our model was based on non-informative priors (Link \& Sauer 2002; Thogmartin et al. 2004). All prior random and fixed effects were designed to have standard normal distributions (Fig. 3). Although we could not confirmed normality of the two diversity indices in our data set using the KolmogorovSmirnov test (Shannon $H^{\prime}$, p-value $<0.001$; Simpson $D^{\prime}, \mathrm{p}$ value $<0.001)$, both indices did not have extreme dispersion (The means $\pm \mathrm{SD}$ of $H^{\prime}$ and $D$ were $1.09 \pm 0.41$ and $0.56 \pm$ 0.19 , respectively) and histograms of both indices had one peak around the mean values. Thus, the variance of each prior diversity index distribution $(V)$ was also designed to have a standard normal distribution.

\section{Fitting the Hierarchical Model}

To fit the hierarchical models, we used WinBUGS (The BUGS Project 2008) and R version 2.4.1 software (R Development Core Team 2008) with the R2WinBUGS package to conduct a Markov Chain Monte Carlo (MCMC) analysis using Gibbs sampling. To use the MCMC results, the Markov Chain must change from the initial values into a stationary distribution. We conducted MCMC sampling for 100,000 counts and discarded the initial 30,000 as burn-in. In addition, to minimise results affected by the initial values, we conducted an analysis of three sets of initial values during MCMC sampling. We used $\mathrm{R}$ to generate randomsampling initial values and evaluated the contribution of fixed effects using a posterior predictive check based on a $95 \%$ confidence interval.

\section{RESULTS}

The means $( \pm \mathrm{SD})$ of Shannon $H^{\prime}$ at confluence and single-flow units were $1.22 \pm 0.32$ and $1.07 \pm 0.41$, respectively, and the means of Simpson $D$ ' at confluence and single-flow units were $0.62 \pm 0.15$ and $0.52 \pm 0.20$, respectively. The mean values of SPI at confluence and single-flow units were $931.57 \pm 808.00$ and $631.11 \pm 705.49$, respectively. The mean areas of vegetation in confluence and single-flow units were 103,106.8 $\pm 53,742.2 \mathrm{~m}^{2}$ and 90,994.7 $\pm 62,312.0 \mathrm{~m}^{2}$, respectively.

Our hierarchical Bayesian-model analysis revealed that all fixed effects had significant positive effects on Shannon $H^{\prime}$ (the 95\% confidence interval did not include 0 ; Table 2 ). Simpson $D^{\prime}$ was positively affected by the presence of a confluence and area of vegetation but was not significantly affected by SPI (the $95 \%$ confidence interval included 0 for SPI; Table 3).

Table 2. Quantiles (2.5\%, 50\%, and 97.5\%) of Posterior Distributions of Shannon Diversity Index $\left(H^{\prime}\right)$

\begin{tabular}{|c|c|c|c|c|c|}
\hline \multirow{2}{*}{ Parameter } & \multirow{2}{*}{ Mean } & \multirow{2}{*}{ S.D } & \multicolumn{3}{|c|}{ Values for the Following Percentiles } \\
\cline { 5 - 6 } & & & $\mathbf{2 . 5 \%}$ & $\mathbf{5 0 \%}$ & $\mathbf{9 7 . 5 \%}$ \\
\hline \hline Confluence & $7.59 \times 10^{-2}$ & $2.50 \times 10^{-2}$ & $2.65 \times 10^{-2}$ & $7.61 \times 10^{-2}$ & $1.25 \times 10^{-1}$ \\
\hline SPI & $4.10 \times 10^{-5}$ & $1.39 \times 10^{-5}$ & $1.38 \times 10^{-5}$ & $4.10 \times 10^{-5}$ & $6.83 \times 10^{-5}$ \\
\hline Vegetation area & $1.27 \times 10^{-6}$ & $2.96 \times 10^{-7}$ & $6.82 \times 10^{-7}$ & $1.27 \times 10^{-6}$ & $1.84 \times 10^{-6}$ \\
\hline Deviance & $-4.12 \times 10^{2}$ & $4.83 \times 10^{2}$ & $1.53 \times 10^{3}$ & $-3.37 \times 10^{2}$ & $3.04 \times 10^{2}$ \\
\hline Intercept & $2.24 \times 10^{0}$ & $3.54 \times 10^{0}$ & $4.24 \times 10^{-1}$ & $6.37 \times 10^{-1}$ & $1.36 \times 10^{1}$ \\
\hline
\end{tabular}

Table 3. Quantiles (2.5\%, 50\%, and $97.5 \%)$ of Posterior Distributions of Simpson Diversity Index $(D)$

\begin{tabular}{|c|c|c|c|c|c|}
\hline \multirow{2}{*}{ Parameter } & \multirow{2}{*}{ Mean } & \multirow{2}{*}{ S.D } & \multicolumn{3}{|c|}{ Values for the following percentiles } \\
\cline { 4 - 6 } & & & $\mathbf{2 . 5 \%}$ & $\mathbf{5 0 \%}$ & $\mathbf{9 7 . 5 \%}$ \\
\hline \hline Confluence & $3.33 \times 10^{-2}$ & $1.27 \times 10^{-2}$ & $8.20 \times 10^{-3}$ & $3.33 \times 10^{-2}$ & $5.85 \times 10^{-2}$ \\
\hline SPI & $1.32 \times 10^{-5}$ & $7.05 \times 10^{-6}$ & $-6.62 \times 10^{-7}$ & $1.32 \times 10^{-5}$ & $2.71 \times 10^{-5}$ \\
\hline Vegetation area & $3.97 \times 10^{-7}$ & $1.53 \times 10^{-7}$ & $9.59 \times 10^{-8}$ & $3.98 \times 10^{-7}$ & $6.94 \times 10^{-7}$ \\
\hline Deviance & $-2.38 \times 10^{3}$ & $2.58 \times 10^{2}$ & $-2.93 \times 10^{3}$ & $-2.36 \times 10^{3}$ & $-1.94 \times 10^{3}$ \\
\hline Intercept & $1.15 \times 10^{0}$ & $1.06 \times 10^{1}$ & $2.55 \times 10^{-1}$ & $8.82 \times 10^{0}$ & $3.18 \times 10^{1}$ \\
\hline
\end{tabular}

\section{DISCUSSION}

Our finding that confluence sites exhibited high vegetation-patch diversity in rivers in Hyogo Prefecture is the 
first empirical support of the existence of confluence effects related to biological habitat diversity within riparian areas. Both the Shannon and Simpson diversity indices for vegetation patches were higher for confluence units than for singleflow units. Even though our results revealed a diversity pattern for roughly classified vegetation types, this type of pattern still provides a useful basis for investigating and understanding the process by which habitat diversity is maintained in riparian ecosystems.

Channel disturbances are amplified at confluences because these locations are points that accumulate water, sediments, and woody debris (Benda et al. 2004a; Benda et al. 2004b; Rice et al. 2006; Rice et al. 2008). Water movement can strongly affect the distribution of vegetation types throughout floodplains, as such forces alter the physical structure and stability of the habitat through erosion and sedimentation (Salo et al. 1986). Debris flows and sediment deposits result in topographic heterogeneity around river confluences (Benda et al. 2004b). Together with our results, these findings suggest that habitat diversity increases around river confluences because these areas have unique hydrodynamic features and subsequently amplify disturbance regimes. High habitat diversity generally corresponds to high diversity in plant species (Wagner et al. 2000). In fact, we found that plant species diversity was enhanced by the flooding-induced creation of bare ground around confluences of the river system in this study (Osawa et al. 2010). In turn, high plant diversity provides diverse habitats and food sources for animals (Qian \& Ricklefs 2008). Thus, the highly diverse vegetation patches around river con-fluences may harbour many plant and animal species in river ecosystems. Future research should examine the detailed processes by which debris and sediment deposition and flooding disturbances enhance the establishment of diverse vegetation types and plant species.

In our analyses, we successfully regulated the effects of SPI and vegetation area in the models, and both factors affected vegetation diversity. For example, SPI positively affected the Shannon diversity index. SPI is conventionally used as an index of the erosive power of flowing water (Wilson \& Gallant 2000) and can be used as a representation of disturbance intensity. Relatively strong disturbances likely occurred in high SPI areas, forming various types of vegetation patches, which points to the importance of disturbance for habitat diversity. Vegetation area positively affected both the Shannon and Simpson indices. The RNER program was conducted throughout alluvial (from mid to downstream) river areas that were surrounded by mainly urban and/or agricultural areas (Hyogo Prefecture 2007). One possible explanation for the positive relationship between diversity indices and vegetation area is that smaller vegetation areas are indicative of the intensification of artificial habitat alterations.

To the best of our knowledge, our study is the first to demonstrate that river confluences may generate habitat diversity for plants in riparian areas, although the results should be interpreted with a little caution because of the failure of our data to meet some assumptions concerning normality of the diversity indices in the analyses. A linear perspective on river networks (i.e., the river continuum concept; Vannote et al. 1980) has dominated much of river ecology over the last 20 years (Fisher 1997), despite the recognition that river networks are branched with tributaries that interrupt gradual downstream changes in channel and valley morphology (Benda et al. 2004a). Recently, the network dynamics hypothesis has articulated the relationships among key attributes of river networks and the patchy heterogeneity of the fluvial process and form (Benda et al. 2004a; Benda et al. 2004b). Our results present empirical evidence of this more recent discontinuum perspective in river ecology, in which river confluences are considered key elements within a dendritic river network. Future research should examine confluence effects in a diversity of freshwater riverine systems (e.g. Fernandes et al. 2004), with particular focus on the fact that confluences vary in geomorphic features, such as shape and scale, within and among watersheds. Such variation in geomorphic features may produce different confluence effects on biodiversity (Benda et al. 2004b).

\section{ACKOWLEDGEMENTS}

We would like to thank the staff at the Ecology Division of the Museum of Nature and Human Activities Hyogo for their valuable support, and the staff at the Laboratory of River Environment LLP for supplying the Research about the Natural Environment of Rivers data set. We also thank Dr. M. Akasaka for commenting on an early version of this manuscript.

\section{Appendix}

Appendix 1. List of Communities that Belong to each Vegetation Type in the RNER Data Set. All Scientific Names are Referred to YList, (http://bean.bio.chiba-u.jp/bgplants/ylist_main.html)

\begin{tabular}{|l|l|}
\hline \multicolumn{1}{|c|}{ Vegetation type } & \multicolumn{1}{c|}{ Community name } \\
\hline \hline Miscanthus sacchariflorus dominant vegetation & Miscanthus sacchariflorus community \\
\hline Phragmites communis dominant vegetation & Phragmites australis community \\
\hline Phragmites japonica dominant vegetation & Phragmites japonica community \\
\hline Salix gracilistyla dominant vegetation & Salix gracilistyla community \\
\hline
\end{tabular}




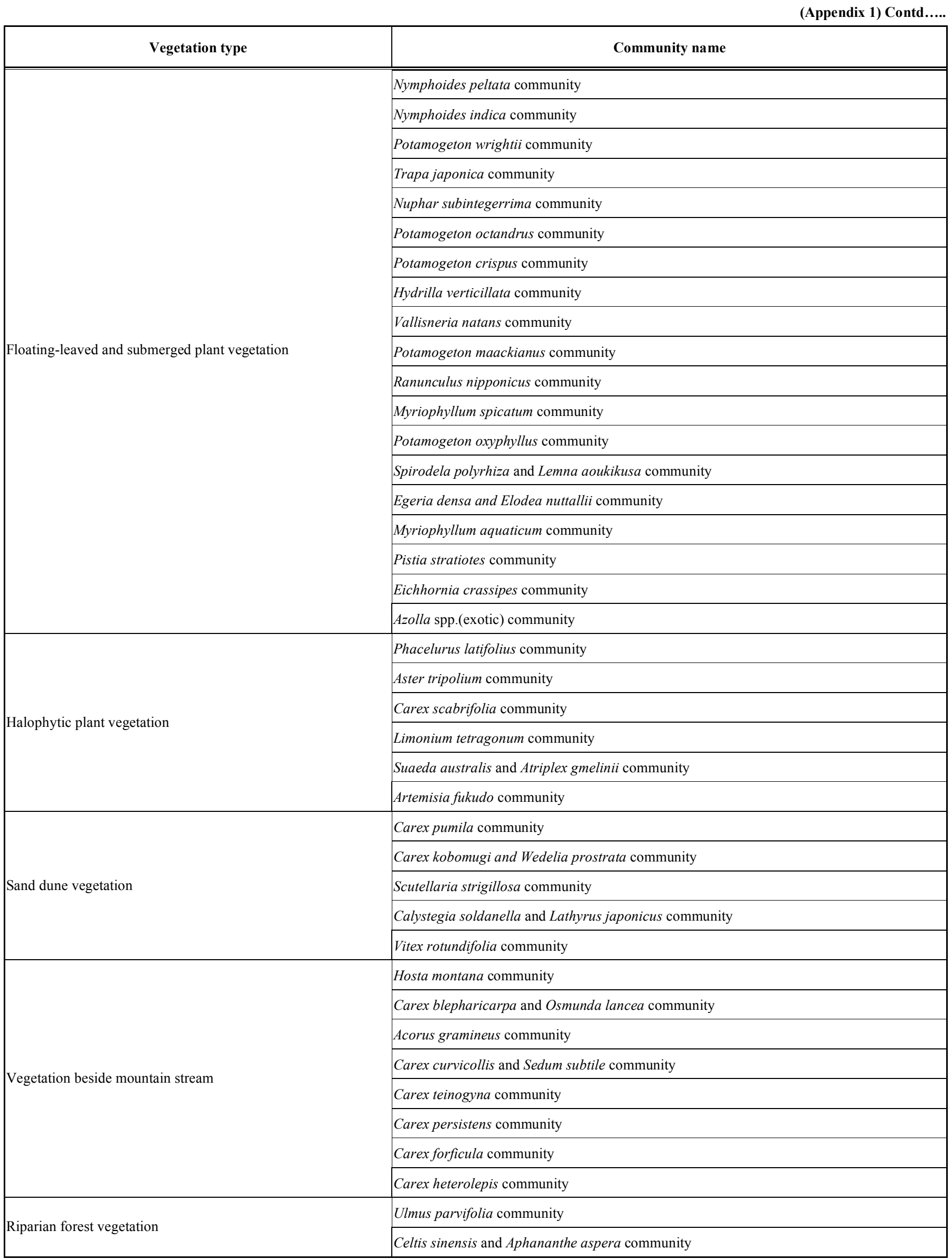


(Appendix 1) Contd.....

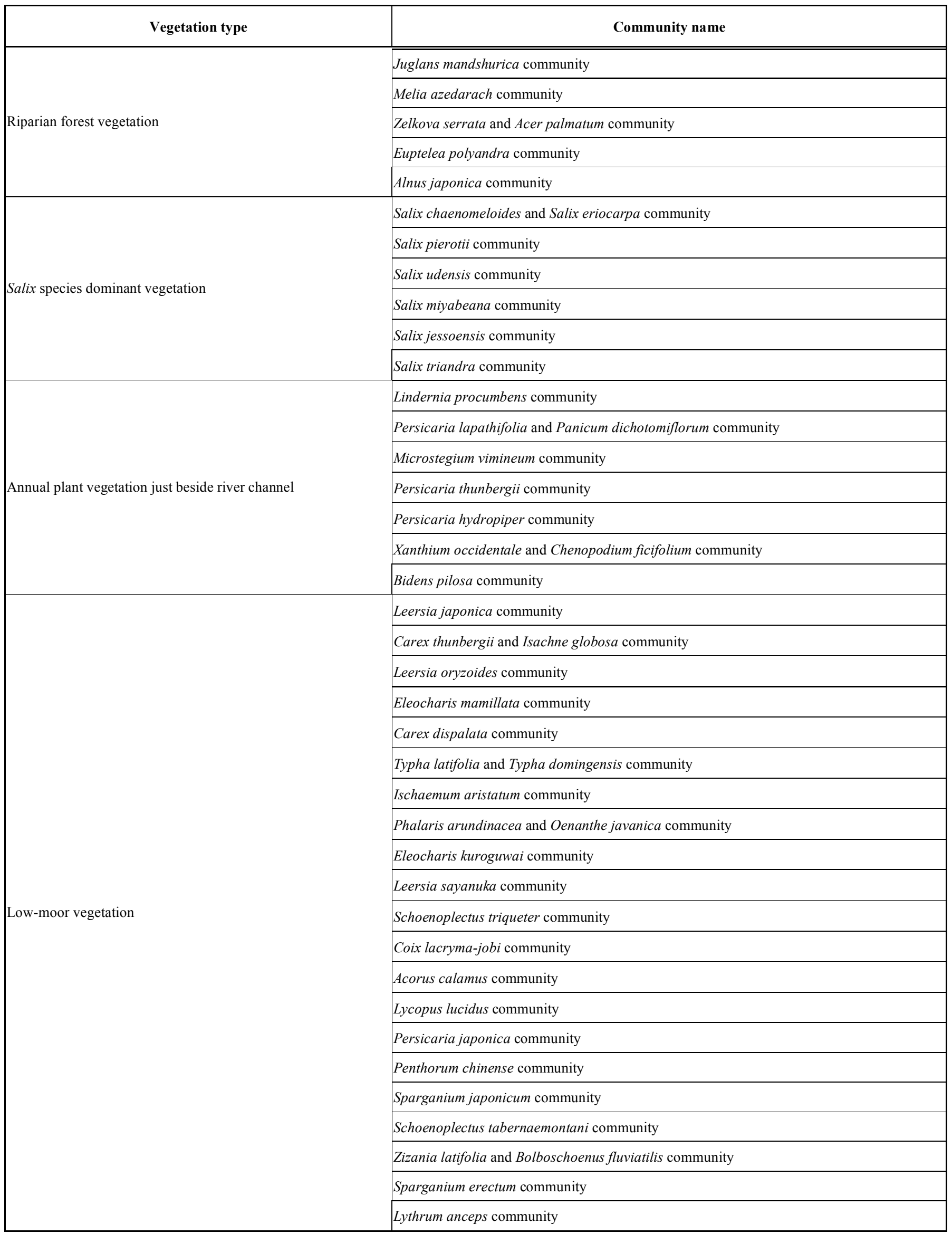


(Appendix 1) Contd.....

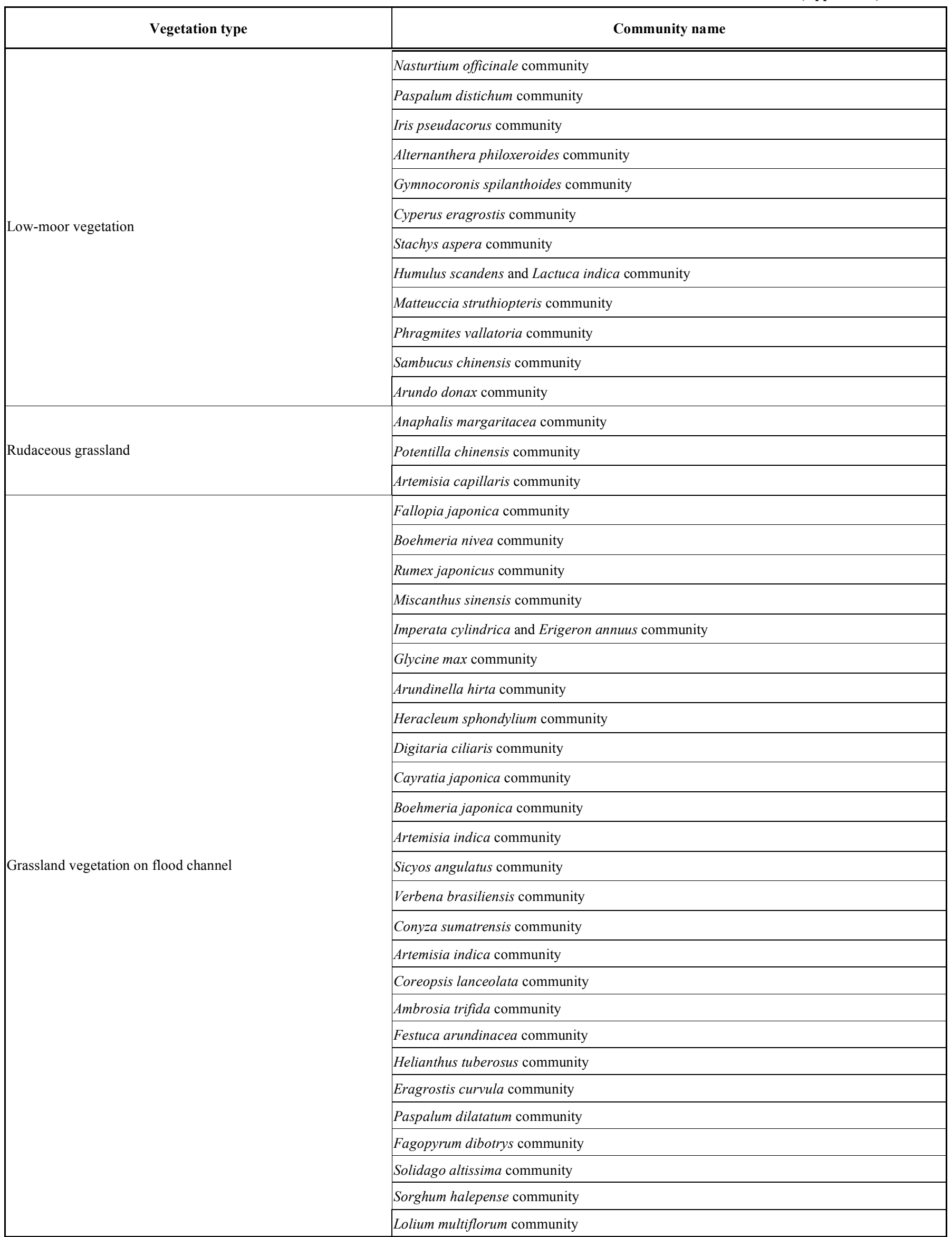


(Appendix 1) Contd.....

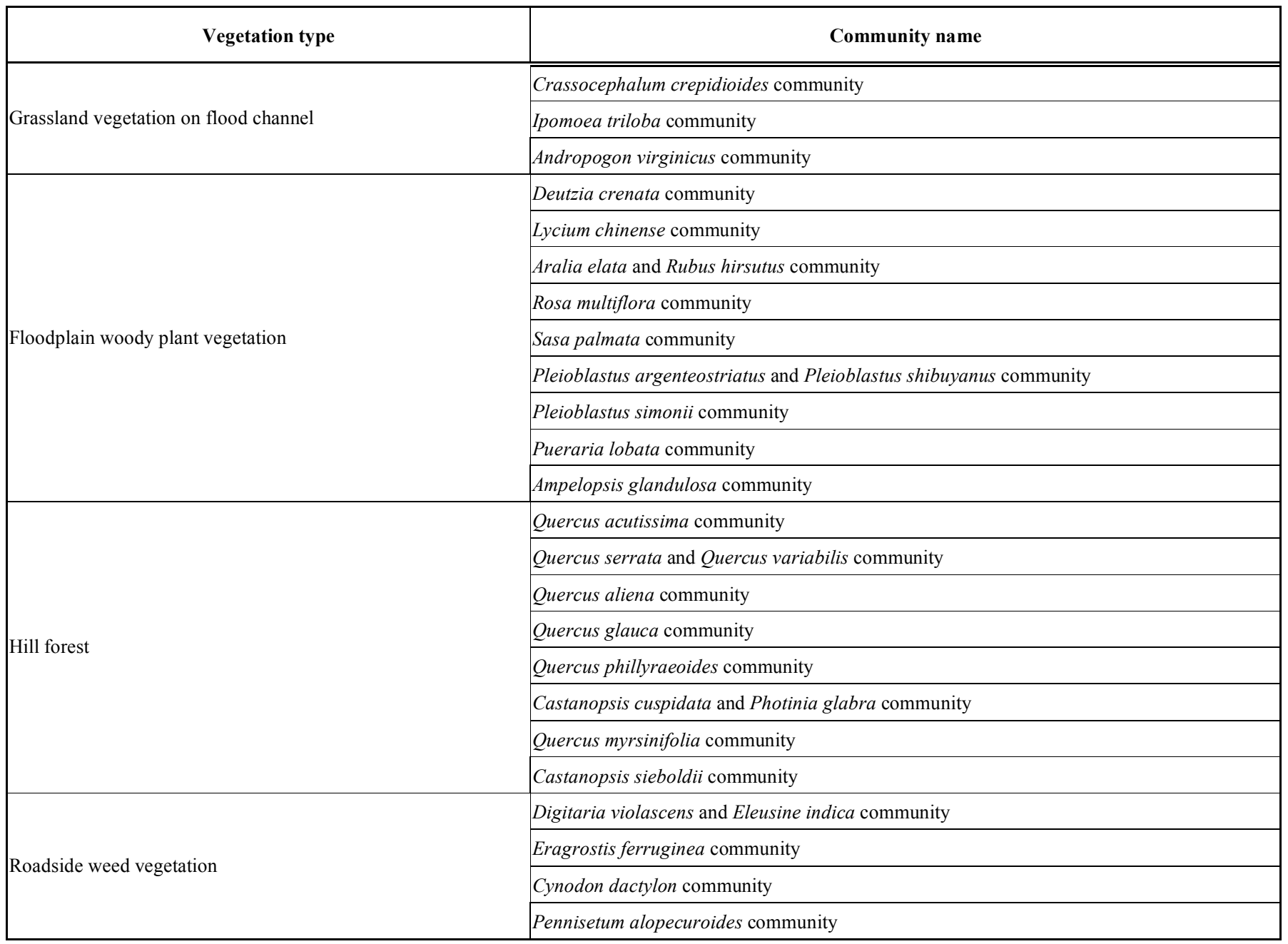

\section{REFERENCES}

Benda, L, Andras, K, Miller, D \& Bigelow P (2004a) Confluence effects in rivers: Interactions of basin scale, network geometry, and disturbance regimes. Water Resource Research, 40, W05402.1-15.

Benda, L, Poff, NL, Miller, D, Dunne, T, Reeves, G, Pess, G \& Pollock, M (2004b) The network dynamics hypothesis: How channel networks structure riverine habitats. Bioscience, 54, 413-27.

Burkart, M (2001) River corridor plants (Stromtalpflanzen) in Central European lowland: a review of a poorly understood plant distribution pattern. Global Ecology and Biogeography, 10, 44968.

Clark, JS, Mohan J, Dietze, M \& Ibanez, I (2003) Coexistence: How to identify trophic trade-offs. Ecology, 84, 17-31.

De Serres, B, Roy, AG, Biron, PM \& Best, JL (1999) Three-dimensional structure of flow at a confluence of river channels with discordant beds. Geomorphology, 26, 313-35.

Fernandes, CC, Podos, J \& Lundberg, JG (2004) Amazonian ecology: Tributaries enhance the diversity of electric fishes. Science, 305, 1960-62.

Fisher, SG (1997) Creativity, idea generation, and the functional morphology of streams. Journal of the North American Benthological Society, 16, 305-18.

Grant, EHC, Lowe, WH \& Fagan, WF (2007) Living in the branches: population dynamics and ecological processes in dendritic networks. Ecology Letters, 10, 165-75.

Haddad, NM, Holyoak M, Mata, TM, Davies, KF, Melbourne, BA \& Preston, K (2008) Species' traits predict the effects of disturbance and productivity on diversity. Ecology Letters, 11, 348-56.
Hyogo Prefecture (2002) Official research manual of Research of Natural Environment of River.

Hyogo Prefecture (2007) Research of Natural Environment of River, Atlas.

Hyogo Prefecture (2009) A guideline for riparian vegetation classification in Hyogo Prefecture, improved edition.

Keitt TH, Bjornstad ON, Dixon, PM \& Citron-Pousty, S (2002) Accounting for spatial pattern when modeling organism-environment interactions. Ecography, 25, 616-25.

Knick, ST, Rotenberry, JT \& Leu, M (2008) Habitat, topographical, and geographical components structuring shrubsteppe bird communities. Ecography, 31, 389-400.

Link, WA (1999) Modeling pattern in collections of parameters. The Journal of Wildlife Management, 1017-27.

Link, WA \& Sauer, JR (2002) A hierarchical analysis of population change with application to Cerulean Warblers. Ecology, 83, 2832-40.

Lowe, WH, Likens, GE \& Power, ME (2006) Linking scales in stream ecology. Bioscience, 56, 591-97.

May, RM (2006) Network structure and the biology of populations. Trends in Ecology \& Evolution, 21, 394-99.

Montoya, JM, Pimm SL \& Sol, RV (2006) Ecological networks and their fragility. Nature, 442, 259-64.

Naiman, RJ, Decamps, H \& Pollock, M (1993) The Role of Riparian Corridors in Maintaining Resional Biodiversity. Ecological Applications, 3, 209-12.

Osawa, T, Mitsuhashi, H \& Ushimaru, A (2010) River confluences enhance riparian plant species diversity. Plant Ecology, in press.

Qian, H \& Ricklefs, RE (2008) Global concordance in diversity patterns of vascular plants and terrestrial vertebrates. Ecology Letters, 11, 54753. 
R Development Core Team (2008) R: a language and environment for statistical computing. R Foundation for Statistical Computing, Vienna, Austria. URL: http://developer.r-project.org/

Rhoads, BL \& Kenworthy, ST (1995) Flow structure at an asymmetrical stream confluence. Geomorphology, 11, 273-93.

Rice, SP, Ferguson, RI, \& Hoey, TB (2006) Tributary control of physical heterogeneity and biological diversity at river confluences. Canadian Journal of Fisheries and Aquatic Sciences, 63, 2553-66.

Rice, SP, Roy AG \& Rhoads BL (2008) River confluences, tributaries \& the fluvial network. Wiley inc.

Salo, J, Kalliola, R, Hakkinen I, Makinen, Y, Niemela, P, Puhakka, M \& Coley, PD (1986) River dynamics and the diversity of Amazon lowland forest. Nature, 322, 254-58.

Svensson, JR, Lindegarth, M, Siccha, M, Lenz, M, Molis, M, Wahl, M \& Pavia, H (2007) Maximum species richness at intermediate frequencies of disturbance: Consistency among levels of productivity. Ecology, 88, 830-38.

The BUGS Project (2008) URL: http://www.mrc-bsu.cam.ac.uk/bugs/

Thogmartin, WE, Sauer, JR \& Knutson, MG (2004) A hierarchical spatial model of avian abundance with application to Cerulean Warblers. Ecological Applications, 14, 1766-79.

Vannote, RL, Minshall, GW, Cummins, KW, Sedell, JR \& Cushing, CE (1980) The river continuum concept. Canadian Journal of Fisheries and Aquatic Sciences, 37, 130-37.

Wagner, HH, Wildi, O \& Ewald, KC (2000) Additive partitioning of plant species diversity in an agricultural mosaic landscape. Landscape Ecology, 15, 219-27.

Wilson, JP \& Gallant JC (2000) Terrin Analysis-Principle and Applications. New York: John Wiley and Sons, inc.

Received: March 22, 2010

Revised: April 28, 2010

Accepted: April 30, 2010

(C) Osawa et al.; Licensee Bentham Open.

This is an open access article licensed under the terms of the Creative Commons Attribution Non-Commercial License (http://creativecommons.org/licenses/by$\mathrm{nc} / 3.0 /$ ), which permits unrestricted, non-commercial use, distribution \& reproduction in any medium, provided the work is properly cited 